\title{
Obituary - Bruce F. Connell (1927-2019)
}

\section{Luiz S. Toledo ${ }^{1}$}

Published online: 13 January 2020

(C) Springer-Verlag GmbH Germany, part of Springer Nature 2020

September was a sad month for plastic surgery with the passing of our friend and beloved professor Bruce Connell on September 16th at his home in Laguna Beach. He was a plastic surgeon at the Western Medical Center in Santa Ana, Hoag Newport Beach and Laguna Beach (Mission) Hospital in California.

Bruce was born in 1927 in Detroit, Michigan and spent his youth in his beloved state of Alabama. After high school, he was drafted into the U.S. Army in 1946 and sent overseas. Upon being honorably discharged, he attended pharmacy school in Alabama before going on to medical school in Buffalo, New York. He received his surgery training at Los Angeles County Medical Center in L.A. and his plastic surgery training was completed at the Mayo Clinic in Rochester, Minnesota. Bruce settled in Orange County in 1958 and practiced until he retired at the age of 85 . Dr. Connell is widely regarded as the father of the postmodern facelift.

He traveled many times to Brazil and had great influence on Brazilian plastic surgeons, as well as in many surgeons around the world. He dared change many things on facelift surgery. One of his most different tactics is that he did not use compressive dressing after a facelift. He did not use any dressing at all. He asked the patient to sleep with the extended neck so he could inspect any swellings and possible hematomas. In his way of thinking, the dressing did not make any difference. Another of his techniques was the use of a zigzag pre-capillary incision in forehead lifts, very close to the hairline, to avoid extending the forehead and allowing him to reduce the forehead when it was too long. Many points on his technique were

\section{Luiz S. Toledo}

Dubai, United Arab Emirates controversial and he got used to defending himself against doctors who thought different.

When I started presenting internationally in the 1980's, Bruce called me after one of my presentations, took me to the speaker ready room and asked me to show him the lecture.

Then he did something only a great teacher does. Very patiently, he would ask me "why is this slide here? It is not the same quality as the others." To what I replied: "but that it was the only picture I had". He said: "It does not matter. Take it out. You are in the big league now". A lesson I never forgot.

In 2004 I organized one of the Recent Advances in Plastic Surgery Symposiums in Belgrade with Mico Djuricic and invited Bruce. It was a stellar faculty including Daniel

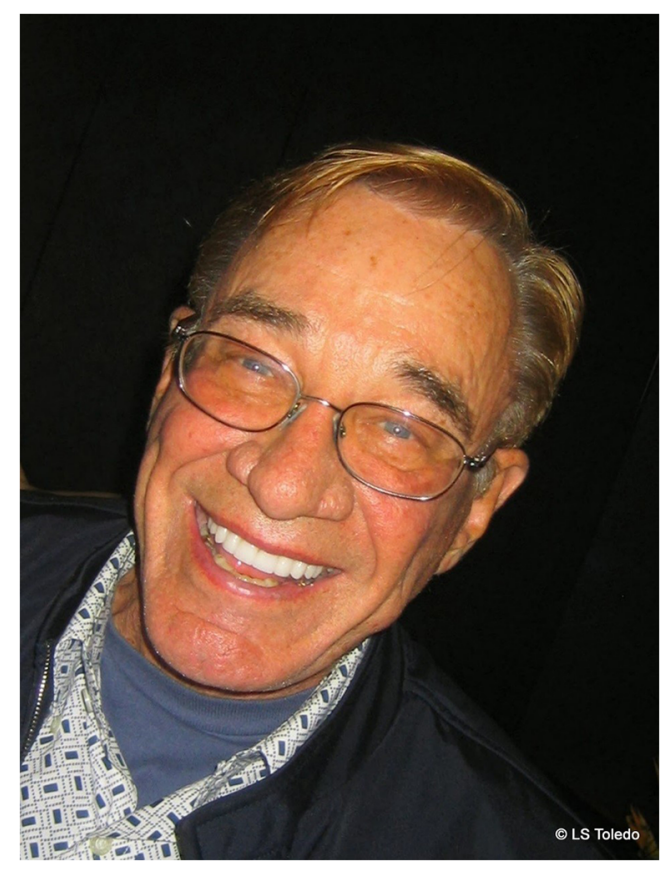

Fig. 1 Bruce Connell, 1927-2019 


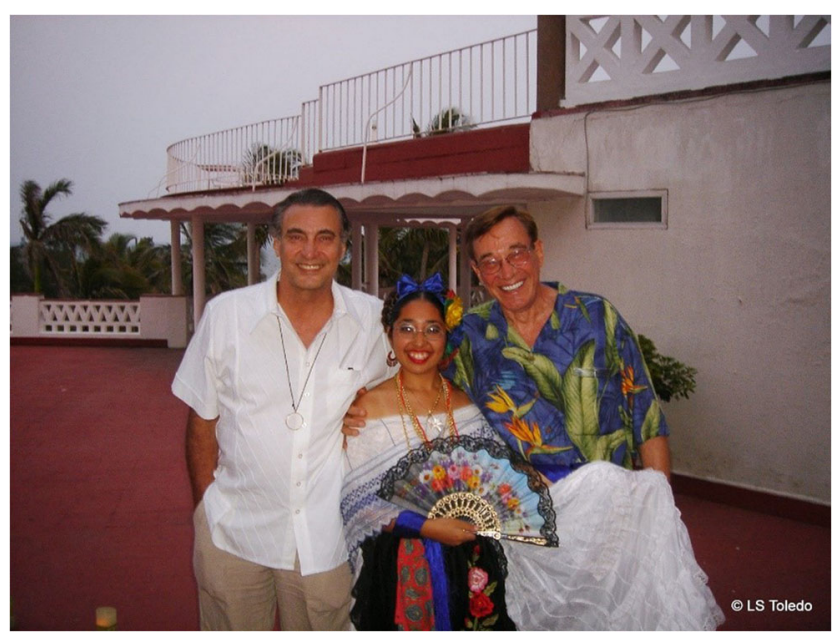

Fig. 2 With Bruce Connell in Mexico, 2005

Baker, from the US, Daniel Marchac, from France, Ithamar Stocchero, from Brazil and Bruce. Usually when we attend meetings, we do not see heated discussions, doctors don't want to cause trouble at the meeting. However, this time, who attended the symposium, could see the "fight" between

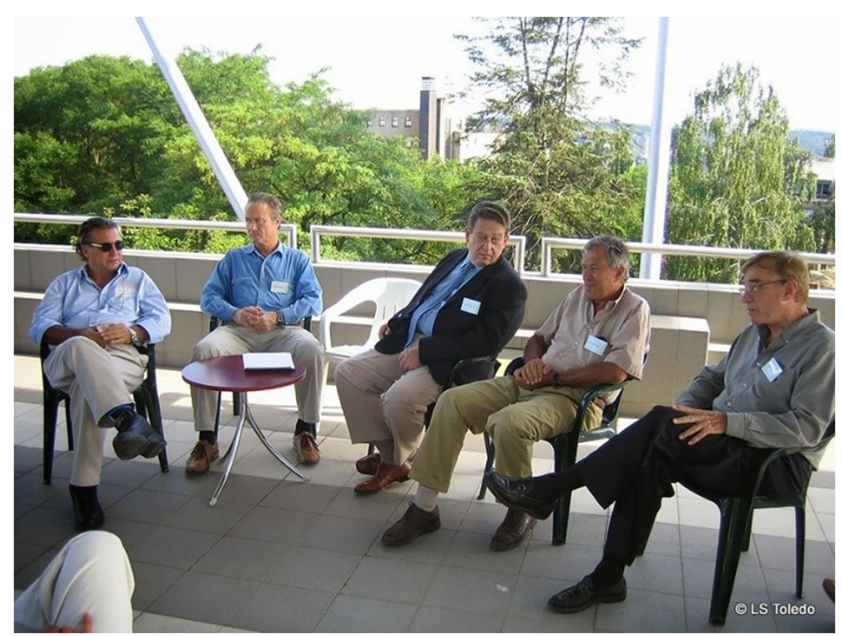

Fig. 3 At the meeting Recent Advances in Plastic Surgery, RAPS IV, in 2004, at the Galathea clinic in Belgrade, Luiz Toledo, Daniel Baker, Ithamar Stocchero, Daniel Marchac and Bruce Connell

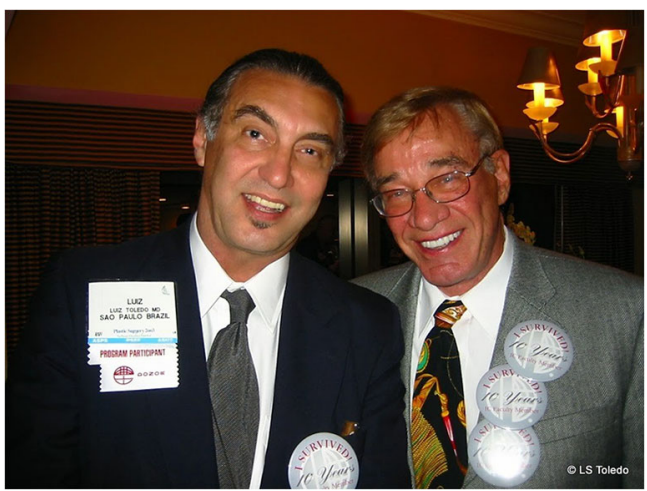

Fig. 4 In San Diego, California, 2004, at the American Congress of Plastic Surgery. I was celebrating over ten years of teaching courses. Bruce, more that 30 years

Daniel Baker and Bruce Connell, each one trying to prove his technique was better. At the end, the winners were all the participants, who could learn in great detail all the intricacies of each facelift technique.

In 2004, the American Society of Plastic Surgery ASPS - held a ceremony during the San Diego Congress to thank the members of the faculty of the teaching courses who had been teaching for more than ten years. They gave us a funny badge saying: "I survived 10 years of ASPS Teaching Courses". As I had been teaching courses at ASPS for fifteen years, I was proud of my badge, but when I saw Bruce, I saw he had three badges, having "survived" more than 30 years of courses. Bruce was well known for his sense of humor and his wonderful teaching skills. He was also a quiet philanthropist for many causes in Laguna Beach and loved spending time partaking in his favorite hobby, planting and gardening.

Even after his retirement from practice in 2013, he continued to teach and give advice to plastic surgeons who would contact him seeking guidance. Recently he was suffering from spinal stenosis, which had completely debilitated him for the past several months. He passed peacefully surrounded by family and longtime friends.

You will be missed Bruce!

Luiz Toledo. 